\title{
La poesía del exilio republicano español y los campos de
} concentración

José Ramón López García

\section{Citer ce document / Cite this document :}

López García José Ramón. La poesía del exilio republicano español y los campos de concentración. In: Exils et migrations ibériques au XXe siècle, $n^{\circ} 6,1999$. 60 ans d'exil républicain : des écrivains espagnols entre mémoire et oubli. pp. 95-112; doi : https://doi.org/10.3406/emixx.1999.1006

https://www.persee.fr/doc/emixx_1245-2300_1999_num_2_6_1006

Fichier pdf généré le 28/08/2018 


\title{
La poesía del exilio republicano español y los campos de concentración
}

\author{
José Ramón López García \\ Universitat Autònoma de Barcelona
}

Como se ha destacado en más de una ocasión, los campos de concentración supusieron para miles de republicanos españoles el primer encontronazo con el exilio que iba a definir sus posteriores vidas, unas lamentables escenas sucedidas en un espacio que fue para muchos de ellos la primera muestra, brutal y efectiva, de lo que las democracias europeas estaban dispuestas a tributar, en triste coherencia con su actitud durante la guerra civil, frente a la agresión fascista. Una parte muy pequeña de la producción poética de nuestro exilio comparte el rasgo común de tener como tema este primer contacto con los campos franceses. Desde la pequeñez testimonial y estética de la mayoría de estos textos se nos ofrece, sin embargo, algo más que la simple lamentación ante las penurias de una serie de experiencias personales. Estos poemas constituyen uno de los ejemplos más explícitos de la crisis del sujeto moderno que en su contemplación y vivencia del horror generado por la propia dinámica de esta modcrnidad comprueba las dobleces del humanismo occidental. Así, la verdadera lección de estos hechos y de la literatura generada a raíz de ellos tiene un alcance mayor, aquél que José María Naharro-Calderón, en dos excelentes ensayos, ha trazado al tratar la significación de la literatura concentracionaria de los exiliados republicanos españoles dentro de la canónica voluntad de olvido ejercida por el discurso humanista burgués, humanismo « que basa su existencia en la simultánea presencia del otro y su exclusión " y que establece un hilo de continuidad evidente entre las manifestaciones exterminadoras de totalitarismos como los « franquistas, hitlerianos, estalinianos u otros compañeros de viaje " y los distintos episodios que a lo largo de la historia se igualan como estructuras de « la violencia colonial » [1998b, 65-66]. Estas obras, en el caso del exilio español, advierten de que no existe «memoria más incómoda para esta amnesia » que la que NaharroCalderón denomina, frente a otras reglas de formación discursiva monumentales, como «intramemoria », la «vacuna » que logra hacer 
pervivir la conciencia de nuestra otredad ${ }^{1}$. Un « espacio abyecto » donde se concentra esa « mayor dosis de gérmenes y anticuerpos para mantenernos en el estado febril de la duda y el inconformismo ante la objetivación de la memoria y la repetición de la barbarie » que hallamos sobre todo en los géneros tradicionalmente no considerados como literarios (testimonios, autobiografias, cartas, diarios) [1998b, 64], pero también en los a menudo atípicos discursos en los que se ha poetizado este episodio ${ }^{2}$.

Con ello se plantea la misma integración en la modernidad que ensayos como los de Zygmunt Bauman demandan al analizar la relación de esta modernidad con el Holocausto, pues sin la revisión de estos hechos, y, por lo tanto, sin la lectura de los testimonios que nos los pueden hacer presentes, estamos ante una inmunología de falsa ejecución [1997]. Pero tampoco habría que olvidar que, como ha explicado Marshall Berman, la experiencia de la modernidad es también la de la disolución de los estados sólidos en la atmósfera del sujeto moderno que ya anunciara Karl Marx [1991]. A este proceso soluble parece referirse el Guillén cercado por la historia de Clamor : «Campo de humillación, / De concentrada humillación, de agravio / Completo... / Entre aquellos alambres / El lento asesinato va extendiéndose / Por cámaras / De gas y de razón, / Y los ayes son humos / Frente a nuestra vergüenza " $[1957,192]$. Si el humo de los crematorios de Auswitzch significó la disolución más horrendamente material del humanismo propugnado desde las filas de esta razón moderna, las experiencias de este siglo de exilios suponen de manera idéntica la quema de buena parte de sus creencias y proyectos. Porque estamos, en suma, ante la importación del

${ }^{1}$ Naharro-Calderón destaca otras dos formas en las que la memoria puede apuntar o hacia este sedante amnésico del olvido (la inframemoria) o hacia la mitificación canónica que anula su capacidad crítica (la supramemoria).

${ }^{2}$ En este sentido, en más de una ocasión se ha aludido, por parte de críticos e historiadores y por sus mismos protagonistas, a las diferencias que separaron al exilio de los intelectuales del de todos aquellos otros españoles empujados a los campos de concentración. Sin entrar ahora en la evidencia de esta distancia entre los diferentes estratos sociológicos de nuestro exilio, lo cierto es que también la intelectualidad republicana exiliada padeció, en la representación de una parte de sus miembros, la terrible inauguración de su nueva condición con su entrada en los campos franceses. Una distancia que también existió, salvo excepciones puntuales (Aub, Altolaguirre, Gil-Albert o Serrano Plaja), en el caso de los poetas y que no han dejado de recordar voces literarias de menor "importancia" en el canon del exilio literario como Amieva [Poeta en la arena, 1964] o Guereña $[1998,641]$. Sin que esta «ausencia de personalidades literarias », como ha recordado Serge Salaün, sirva para justificar las limitaciones de buena parte de la poesía escrita en los campos [1996, 359]. 
colonialismo a Europa que supuso la extensión de los fascismos, un movimiento que revela todas las miserias del liberalismo humanista europeo y que condujo, como denunciara Hanna Arendt y retoma Naharro-Calderón, a la racionalización de la muerte por parte de la política. En el caso español, a los supervivientes de los campos franceses todavía les quedaba, tras su salida, un largo recorrido plagado de decepciones que terminarían concluyendo en la ignominia de casi cuarenta años de régimen franquista. Las nuevas certezas las habrían de buscar ya otros, para la mayoría de los desterrados quedaba el enquistamiento en los ejes de sus pilares ideológicos y estéticos, la huida mediante creaciones alejadas de la realidad devastada que dejaban tras de sí, los más o menos logrados intentos de restitución compensatoria $o$, y nada más justo y comprensible, la queja (irónica o no), la melancolía, el lamento (amargo o resignado), la rabia, el más que previsible desencanto o la inconmovible y costosa permanencia en la lucidez. Una lucidez en la que algunas veces, como en el caso de Max Aub, les sitúa de lleno su periplo concentracionario, creando unas obras en las que, con las limitaciones que la escritura de cada individualidad supuso, la confianza en la vigencia final de la expresión literaria se alza como una reacción estéticamente instintiva frente al horror. La lectura de esta vivencia se nos hace así ineludible si queremos reconstruir la nueva solidez de nuestra actual condición y confiar en que su disolución sea emancipadora.

Algunos críticos como Alvin $\mathrm{H}$. Rosenfeld, tomando prestadas en su caso las palabras de Elie Wiesel, consideran que la literatura generada por el Holocausto, de evidentes concomitancias con nuestro tema sin por ello anular la separación de ambos episodios en la sistemática voluntad exterminadora del nazismo, es el recuerdo de una doble muerte : « not only man died but also the idea of man ". Pero también toda esta producción se sustenta en la paradoja de la imposibilidad y a la vez la necesidad de una escritura acerca de la muerte de la idea del ser humano con el objeto de sostener esta misma idea amenazada [1988, 5 y ss.]. Para ello no todos los poemas escritos en estas circunstancias se refieren con voluntad testimonial a lo ocurrido entre las alambradas. La poesía escrita durante el encierro en los campos revela muy a menudo una capacidad de abstracción de la realidad inmediata. Son ejemplos donde la literatura actúa como válvula de escape y que hasta pueden referirse a imágenes de añorada perfección universal : «En este instante preciso, / de esta tarde singular, / el cielo ha 
escanciado / sobre las cosas / un armisticio total ${ }^{3}$ ». Así, Serge Salaün ha señalado cómo la labor cultural desarrollada en los campos incluyó, en sus meritorias publicaciones, páginas poéticas donde se produce una inversión de la épica del Romancero de la guerra civil al intimismo : " on ne chante plus l'Histoire mais un Moi douloureux et pudique, tourné vers l'amour, la solitude, la mort, avec de fugitifs échos du vécu glorieux de la guerre : quant aux camps, ils sont pratiquement éludés (dans les collections consultées). L'heure n'est plus à l'épopée, à la voix collective (malgré quelques timides tentatives), à l'expression individuelle d'un destin national " [1989, 123124]. Y es que, como ha ampliado el mismo Salaün, « la poesía no tiene ya la fuerza de hacerse cargo de la Historia $»[1996,358]$.

Sin embargo, no toda la poesía generada en estas circunstancias o que las recupera con posterioridad remite a esta pérdida, es más, en muchos casos actualiza esta capacidad histórica independientemente de su desplazamiento de las fuentes canónicas que han reconstruido después la historia oficial. Son varios los rasgos comunes en este conjunto de composiciones, pero existe uno en concreto que parece especialmente iluminador para la comprensión que de esta poesía (y por extensión de la literatura concentracionaria) podemos extraer. Me refiero al motivo del cuerpo enfermo o herido que se despliega ante nuestros ojos como imagen superpuesta de los distintos niveles de esta dolencia : desde el cuerpo sometido a la degradación física y psicológica de la vida en los campos, que se ve reducido a la pérdida de su identidad y sólo puede contemplarse en el espejo abyecto de sus compañeros, hasta el cuerpo superior de las coordenadas espacio-temporales y la construcción histórica, pasando por la herida abierta en el lenguaje como receptáculo del espanto vivido. De este modo, no resulta para nada sorprendente la relación que establecen estos

${ }^{3}$ Efrén [Hermida], «Letras ", Boletín Profesionales de la enseñanza, Argelès-sur-Mer, s.f., s.p. [reproducido en Villegas, 1989, 90]. En el mismo monográfico se pueden consultar composiciones, de ésta y de otras publicaciones realizadas en el interior de los campos franceses, de parecida factura y significación [32-33, 43, 47 ó 74]. El impulso inicial de muchos de estos poemas es el descrito por Manolo Valiente: « $i$ Cómo es posible no morir de nostalgia, de recuerdos recientes y de tristeza en esos momentos! ¡Cómo no dejarse arrastrar por la desesperanza y abandonar la lucha por la vida! Para salir de ese círculo de angustia, Juan, instintivamente, se dio cuenta de que el único medio de evadirse no podia ser otro que el de escribir; y escribir poesía [...] porque es la forma más pura de la evasión hacia otro plano de la realidad [...]. Tanto es asi que cada vez que sus sufrimientos físicos lo dejaban tranquilo, escribía. En estas circunstancias nacieron pedazos de destino interrumpido e imágenes de esperanza, muertas " $[1997,10]$. 
versos entre los cuerpos sarnosos, famélicos, devorados por los parásitos, y los macrodiscursos de la política, la historia, el lenguaje y el concepto ideal del ser humano que los detenta. Con ello nos recuerdan cuál es el sentido de la herida y su carácter infeccioso, su imposible cauterización, más allá de que se cubra el espejo de esta otredad bajo la arena concentracionaria del olvido.

Gracias al valioso testimonio de Juan Gil-Albert en Memorabilia podemos conocer con bastante detalle lo que supuso el internamiento en Saint Cyprien de buena parte del llamado grupo de Hora de España. Uno de sus integrantes, Arturo Serrano Plaja, indicó el alcance de esa, como escribe Gil-Albert, «broma trágica » sobrellevada «con dosis iguales, y alternativas, de depresión y comicidad », cuando le afirmó : « esto nos ha sellado; siempre seremos ya unos parias » $[1975,267]$. Y no otra cosa traslada Serrano Plaja pocos años después al molde de uno de los sonetos que integran su primer poemario en el exilio, Versos de guerra y paz (1945), el titulado «Campo de concentración » : «El suelo era de arena olvidadiza / donde no imprime rastro la pisada. / Y el cielo era penoso a la mirada / que ya sin esperanza era ceniza. // De aquella España oscura y de su liza / tan pura, y tan reciente y tan llorada, / apenas si una turba abigarrada / quedaba de su estirpe primeriza. // Aquello que fue gloria, era miseria. / Cuanto hubo de orgulloso, fue humillado. / Los héroes, carcomidos por piojos, // más que alzada bandera, eran despojos, / memoria corrompida de soldado, / tristísimo espectáculo de feria " [1982, 102]. Serrano Plaja describe con amarga lucidez la victoria de los fascismos europeos sobre la construcción idealista de la lucha española antifascista : olvido, ceniza, turba, miseria, humillación, despojos, todo apunta a lo que es ya una materia corrompida que expulsa las condiciones de posibilidad del heroísmo humanista. Y dicha conclusión es transmitida mediante la asociación de la memoria a la materialidad corporal y su proceso de descomposición. Si el diagnóstico es certero, la amnesia que el espacio acotado por la arena y el mar estaba ya delimitando, lo que en este momento no se trasluce de manera tan obvia es el alcance de esta derrota, la manifestación de los límites del humanismo occidental burgués que, como parte de sus estrategias de ocultación, opta por el olvido histórico y las máscaras falsas de supuestos constructos racionales para velar. las conexiones entre liberalismos y totalitarismos [Naharro-Calderón, 1998b].

Bien distinta fue la reacción de Gil-Albert y él mismo lo ha explicado en Los días están contados cuando evoca su estancia junto a sus compañeros en La Mérigotte, la casa de campo de Poitiers del escritor Jean-Richard Bloch 
en la que fue acogido con sus compañeros en la primavera de 1939 tras su salida del campo de concentración [Aznar Soler, 1991]. Me interesa ahora destacar el juicio de Gil-Albert sobre su circunstancia porque apunta de nuevo a la metáfora corporal : "pertenecíamos "aún" a un organismo que sangraba y puede que entonces cada uno de nosotros éramos a manera de un herida sobre un cuerpo convulso. $Y$ las heridas se engangrenan o se restañan; no hay más. En unos se restañaron y en otros... » $[1974,129]$. Sánchez Barbudo, recordando el mismo episodio, ha expuesto muy bien la contradicción interna en la que vivieron esos meses : « todos gozábamos con avidez de aquello : el lugar, la paz, las deliciosas comidas, música y libros, la primavera. Pero a menudo se mezclaba a nuestro goce no poco de remordimiento. Parecía vergonzoso abandonarse a tan sereno bienestar. Nos sentíamos todos, de algún modo, culpables. [...] sentía vergüenza a la vez que alegría de estar vivo [y] veía con reproche esa tendencia al olvido que observaba en mí mismo, y que de un modo tan obvio se manifestaba en GilAlbert » [1980, 60-61]. Naharro-Calderón ha recordado al respecto la indicación de Primo Levi de que la supervivencia de los campos « es una marca de inferioridad, una radical muestra de inhumanidad y vergüenza » $[1998,321]$ porque estigmatiza al sujeto que sabe que ha sobrevivido bien porque su condición especial, en este caso por su "privilegio" intelectual, ha facilitado su salida del infierno, bien porque ha superado lo inhumano de la única manera posible, deshumanizándose él mismo. Ello plantea un conflicto irresoluble si no se ejerce una función sublimatoria, como la que puedan significar todos estos textos aquí comentados, o se opta directamente por el olvido o la locura, ya que pronto se advierte la imposibilidad de vivir permanentemente en el epicentro del horror. Así, encontramos circunstancias extremas, como el patológico sentimiento de culpa que Manuel Altolaguirre exhibe en su proyecto autobiográfico de El caballo griego y que le lleva a los límites de una locura directamente asociada con la muerte [1986]. En otros casos, la herida abierta que menciona Gil-Albert se puede cerrar mediante la reincorporación a la esfera de la modernidad canónica ejercida a través de la sensibilidad artística. Y muestra de ello es su poema « Las lilas ", escrito en La Mérigotte, donde, aunque Gil-Albert sea consciente de estar construyendo la primera de sus "ilusiones", se anuncia ya la escéptica lucidez vitalista (que incluye la caducidad o el dolor) de su inmediata poesía mediante la descripción de esas flores que le ofrecen, en su explosión primaveral, un ámbito de engañosa inmunidad: "cada racimo de su despertar / era para mí un retoño de seguridades, / y entre ellas viví engañado como tantas veces, / dedicando los latidos de mi corazón / a la hermosura de 
una sombra, / sombra muda que se interpone entre mi deseo / y la verdad que busco » [Las ilusiones, 78]. Es lo que Sánchez Barbudo llega a entender con el paso de los años reconociendo la dureza de su impresión primera, porque Gil-Albert está apostando por su reingreso en la humanidad de la que ha sido desplazado, está buscando el lugar que le haga olvidar su condición de paria : «aquel abandonarse a la belleza fue para él como un recuperar su propio ser, un retornar a lo que era. Y si hubo egoísmo en tal entrega, en aquel olvido, también hubo como una afirmación, aún tímida, de su derecho a la vida » [61-62]. Pero, con todo, la posibilidad de que el cierre de la herida se produzca en falso queda abierta.

A esta última posibilidad apuntan los poemarios de José Canosa Donate, quien en 1946 edita, en formato bilingüe, Six roses noires pour une blanche, un título cuyo alcance precisa Georges Blanchon en su prefacio al libro: «Six roses noires. Six années de prison, de barbelés, de travail forcé, d'humiliations. [...] Une rose blanche. La liberté » [4]. Canosa Donate poetiza sus experiencias a lo largo de siete composiciones que se datan y sitúan geográficamente con total precisión : "Argèles-sur-Mer-marzo 1939 », « Mayo-Gurs-1939 », « Infierno de las Landas-Enero 1940 », «Cárcel vagón $n^{\circ} 37.774$, sobre una vía muerta. Landas-Diciembre 1939 », «En cualquier parte donde la indignidad exista. Otoño del 42 » y, finalmente, "Grenoble, primavera de 1946 », donde llegaría a ser en el futuro lector español en la Facultad de Letras. Estas referencias constituyen una información espacio-temporal a la que necesariamente se ha de aludir para no perderse en la inhumanidad de su nueva condición, la determinación de fecha y lugar permite seguir inscrito en el devenir histórico que le es negado al infrahumanizarlo. La misma exactitud hallamos en otros casos, como los de Max Aub o Celso Amieva, cuyos poemarios acerca de esta vivencia están igualmente datados y localizados. No se trata sólo de la recuperación testimonial, ni de una sublimación de lo sufrido, se trata también de la protección de la identidad temporal que se les niega y que está profundamente amenazada, pues en los campos se origina ya la futura problemática del exiliado acerca de su identidad. Así, el tiempo del exilio es para Amieva aquél que se constituye con la arena de su actual espacio y lo que en Barcarès es un síntoma más de la enfermedad que denomina « Arenosis », " en el desesperante reloj de arena del exilio » [La almohada de arena, s.p.], veinte años después, en el exilio mexicano, se convierte en una obvia pregunta retórica, " ¿otra cosa que arena es el exilio ? » [Poeta en la arena, s.p.]. La misma arena antropomórfica que se convierte en el 
reverso especular de la nada al ocupar cada una de las acciones físicas y mentales del concentrado : « Todo es arena. / Lo que entra en la cabeza / Y lo que sale. / Todo es arena. / La luz es arena que alumbra. / El fuego es arena. / El dolor es arena que arranca. / Y la arena tiene manos, / Y pies ; / Y anda / Y golpea. / Y todo lo que como es arena. / Y el día es arena ; / Que quiere irse / Que se va / Y la calma no existe. / Es la arena, / La arena, / La arena / Que todo lo arrastra / Hacia la cuenca del cero " [Valiente, 94]. Es la calidad de la experiencia concentracionaria a la que Serrano Plaja alude cuando poetiza su estancia en Saint-Cyprien, esa huella doblemente borrada por las olas de la Historia revisionista y canónica porque la derrota republicana se extendió más allá de la victoria aliada de 1945, aquejando con ello a todo el exilio republicano, y porque, si bien en el caso del Holocausto sí existió un "ajuste de cuentas" con los culpables de la barbarie, en el caso de Francia y de España, el episodio de los españoles en los campos franceses se abre y cierra en « un paréntesis olvidable y una deformación excepcional del sistema universal » [Naharro-Calderón, 1998b, 79]. La negación de la otredad se clausura de este modo sobre sí misma y rehuye la mirada hacia la herida abierta de sus contradicciones, relega, espacial, temporal, física e históricamente, al otro que amenaza una falsa construcción universalista e impide, con ello, su proyección como lección histórica efectiva. Signo de este funcionamiento es el que este afán clasificador alcance mayores implicaciones. Así, Luis Bazal, que dedica dos poemas a sus estancias en Argèles-sur-Mer y Bram, se refiere al compartimiento de los reclusos : « En el campo de Bram... / En la barraca infecta / "sesenta y cuatro", número de serie, / mi cuerpo se aposenta " [1957, 46]. Al igual que Canosa Donate cuando concreta el número de su vagón prisión, la disposición regular de los residentes en los campos es la muestra del aparente orden racional que oculta el hacinamiento infrahumano de las condiciones de vida de los prisioneros. El caos inicial de la invasión de los parias republicanos derrotados en Argelès, en una variación que denunciaba Amieva en su poema « De Argelès al Barcarès ", se convierte en matemática distribución : "Barcarès es el hombre "standard" / en la barraca "standard" / del islote "standard" / con ración "standard" / y disciplina "standard". / Es un castillo de arena / para aburrirse y desesperarse / geométricamente. " [La almohada de arena, sp.] Lo mismo se podría aplicar a la intensa actividad desplegada en el interior de los campos por los propios españoles prisioneros, un trabajo que buscaba suplir su degradación como ciudadanos de tercer grado a través de múltiples proyectos que los rehabilitaran en la esfera de la cultura y del orden social y, 
de paso, en muchas ocasiones, actualizase el sentido político y social del bando republicano durante la guerra civil [Villegas, 1989].

Si retomamos el libro de Canosa Donate, vemos que todas sus composiciones, excepto en un caso, llevan títulos que aluden claramente a las situaciones descritas, "El último surco », « Primavera muerta », "Cuadrilátero », « Resina », " Obsesión » y « Tres líneas ». No es casual la ausencia de título en el poema que justamente sitúa al ser humano, como ya se vio, en la indignidad como una concreta localización espacial, pues sus poemas marcan un progresivo avance hacia la deshumanización y ésta adquiere una significación universal antes de que se alcance la ansiada libertad. En los otros poemas se relatan episodios que aluden a la dureza de los campos o de los trabajos forzados, así en "Resina » donde se menciona la obligatoriedad de talar como mínimo diez árboles pues sino « después... en razón del trabajo a medida, / que exige diez troncos, / cortados por día, / sin pan fué mi cena " [p. 18] $]^{4}$. Pero en éste se nos relata la escalofriante historia de una niña, tuberculosa y sifilítica, que, tras cruzar la frontera, se prostituye para sobrevivir : " Se llama María y, en las alambradas, / quiebran los guardianes sus huesos de niña, / en bárbaras cópulas / que dan miserables, el pan a medida ». El sustento conseguido antes mediante los trabajos forzados se degrada todavía más al implicar ahora la prostitución directa del cuerpo ${ }^{5}$. Pero el avance de extrañamiento del sujeto que observa horrorizado la escena va más allá de la cuantificación alienante de la supervivencia más básica, es el cuerpo infantil de María, que toma los ojos del yo poético como vehículo transmisor de su denuncia, el que personifica la acusación hacia esa indignidad universal : « La vi acusadora / en la celda opaca de esta enfermería, / mostrando en la rosa de un chancro al Derecho / su infancia podrida » [27].

${ }^{4}$ Como ya indicó Javier Alfaya, los campos de concentración cumplían «una doble función: política y económica $[\ldots]$, represiva y de explotación esclavista " $[1976,100]$. Y es que pronto se planteó una solución al problema que suponían los internados, la que Amieva sintetiza, fechada en octubre de 1939, en tres posibilidades: «A España o a la Legión - o a trabajar en un Batallón " [1960, s.p.]. Una solución inicial que después amplió su sentido y "utilidad" a la solución colonialista que certeramente apunta Naharro-Calderón [1998b, 75] y que se ha estudiado en algunas ocasiones [Cohen y Malo, 1994; Rafaneau-Boj, 1995].

5 Véase al respecto lo apreciado por Naharro-Calderón en su comentario de los textos de Silvia Mistral o Neus Català [1998, 318-319]. 
Existe otro poemario de Canosa Donate donde el miserabilismo de la vida en los campos se hace aún más patente. Se trata de un libro que lleva por título Madera, escrito en el año 1939, pero inédito hasta su inclusión en una Antología poética del autor del año 1974. Lo relevante es la explicación que el poeta da para esta larga suspensión : " Este libro no vio la luz, porque vino al mundo ciego " [39]. Aunque Seis rosas negras para una blanca y Madera están al servicio de una misma circunstancia biográfica, el segundo se acerca más a las categorías que a veces se han utilizado en el análisis del Diario de Djelfa de Max Aub, tales como « diario testimonial » o « ficción realista " [López Casanova, 1996; Candel Vila, 1996]. El lenguaje y lo explicado en las doce composiciones de Madera, aunque no exentas de paréntesis líricos, nos sitúa en un explícito realismo que va acompañado de un uso lingüístico convencionalmente menos poético. Un registro que toma como referente principal al cuerpo $y$ sus funciones $y$ degradaciones biológicas en lo que es la imposición del lenguaje menor por encima del metarrelato de la historia y los discursos políticos [Naharro-Calderón, 1998, 314-315]. Así, el poema que da título a la obra remite a la madera como material que metaforiza la composición de esta experiencia (como la arena lo será para Valiente o Amieva) en una clave de humanismo cristiano (también usado por Amieva en su poema « Allez, Allez! » de La almohada de arena) donde componentes substanciales de la persona son anulados: lenguaje, pensamiento, sentimiento, apetito, sexo y temporalidad : « De madera era la lengua, / y de madera la frente, / el corazón de madcra, / y de madera era el diente. [...] / Era el deseo madera / del testículo a la mente. / Madera, y sólo madera, / el pretérito, el presente / salvo la alambrada artera, / nuestro guardián inclemente. // Entre el clavo y la madera, / el hombre : Cristo yacente » [43], yacente en lo que luego es " macabra canción del madero podrido » [50]. A partir de ahí se relata el grado de deshumanización al que se ve sometido por la barbarie de la lógica racional concentracionaria : « un orden inhumano: forja cadenas, / y el hombre encadenado / se vuelve fiera ", con lo cual se impone la capacidad instintiva que se plasma en una inmovilidad temporal de letárgica supervivencia pero también de anulación : " ni horas ni días, / el sentido es letargo, / y sin pan es el hambre / cronología " [47]. También Max Aub alude a la desposesión del tiempo biológico de los prisioneros en su largo poema "Toda una historia » del Diario de Djelfa, donde el ejemplo de Manuel Vázquez González y de otros reclusos castigados en el « campo especial » de Djelfa apunta a esa pérdida y por eso, desde el más joven al más anciano, quedan igualados en la infrahumanidad de sus cuerpos. El problema, de nuevo, es que la apremiante 
necesidad de alimento lleva a un punto de no retorno : "Casanada bien tapado / bajo su manta se come / sus excrementos ${ }^{6}$ ». Y ello implica también un rebajamiento en el terreno del lenguaje, la pérdida de humanidad supone, en tanto que somos seres lingüísticos, una pérdida de la voz: " - No te comas eso, oye. / ¿ ¿Por qué, di, por qué ? Está bueno. / Perdido vocabulario » [55]. La capacidad evocativa, en coherencia con esta privación, puede quedar invalidada en su convivencia con lo excremental : " En el hondo vacío de la pena, / yace el recuerdo. / Los orines en el mar donde navegan, sémenes muertos. / [...] / Las letrinas se queman / en el agrio excremento de los cuerpos » [Madera, 46-47]. Es la misma condición humana degradada a la animalización por la lluvia, " humano anfibio [...] hombre hecho sapo ", revolcada en una "cloaca de esputos y trapos " [Madera, 50-51]. Incluso se reproduce por parte del prisionero la destrucción a la que él mismo se ve sometido cuando busca regocijado sus piojos y se complace en un ritual macabro donde aniquila a aquello que contribuye a la abyección de su ser pero que también le hace sentirse vivo. Así, hurga con las uñas sus « sucias axilas " y sus " rojos codos... " y " sádicos mis dedos / sus yemas marean / al piojo epidérmico / que chupa y te enferma [...] / ¡Clic !... Revienta hermano... / A ver si hallas otro... / Qué placer chafarlos ! / Me pica, me pica... bendita escabiosis / ácaro que excitas, / y mi piel barrenas : con gustos atroces / de baja ramera : / arrancando costras / hasta ver la sangre / en brazos y piernas, / vientres y genitales / en morboso orgasmo / de lujuria infame. / Mi sarna y mis piojos / mi goce callado / de paria en el lodo... / ¡Mis piojos, mi sarna... ! / iya no estoy tan solo ! " [Madera, 5253]. Es el mismo proceso descrito también por Aub en sus deformaciones feístas, cosificadas, animalizadas, de raigambre expresionista y esperpéntica donde, en una descripción muy similar, los internados pierden explícitamente su anterior condición humana : «En el marabú apiñados / seis ex-hombres en montón. [...] / Hijos de sarna y prisión, / engendros del pus francés, / esqueletos de dolor, / escoraciones y piojos, / manto de frío feroz " [Diario de Djelfa, 24-25]. Pero en el caso de Aub hay lugar para el justificado resentimiento hacia los causantes de esta situación que coloca las cosas en su justo sitio : el universo concen-tracionario está apuntando a la herida de una racionalidad occidental cuestionada, que supura para recordar

\footnotetext{
${ }^{6}$ Aunque también el mismo tema se subvierta en otras ocasiones por parte de Aub mediante la ironía expresada con el uso desautomatizado del lenguaje coloquial: "Ya lo dice el refrán: - contra el hambre, alambrada, - noche y día " [33].
} 
que es un cuerpo enfermo, frágil, de fácil desmembración si no se ponen los medios que controlen y recuerden su latente enfermedad.

Amieva plantea la posibilidad de que los exiliados sean « prófugos del Más Allá », pues " perdimos la guerra y perdimos también la paz... », por lo que ni el exilio a América, ni el alistamiento en la Legión francesa, ni el lamento en la reclusión de las playas, ni el retorno a España son posibilidades factibles de realización, pues el « espíritu, muerto », no ha venido con ellos sino que "se ha quedado para siempre allá », en la lucha perdida en tierra española [La almohada de arena, s.p.]. Están todos " muertos y sepultados ya. Y ni siquiera sepultados en tierra, sino en arena. Inclusive los que se fueron a América, que lo sepan o no " [Poeta en la arena, s.p.]. Porque al igual que la guerra civil española fue el trágico prólogo del fascismo bélico europeo, los campos franceses desempeñaron un papel que asumía, en definitiva, los signos de una Europa carcomida en el corazón de sus ideales universalistas de la que Amieva denuncia los signos más evidentes de esta traición : «—Oh señores de Europa / (habrá señores mientras haya lacayos), / sobre todas las quintas columnas / espectaculares colosos de barro ! / [...] / Pero ¿qué sabe Hitler de esto / ni todos los vicetiranos / que beben agua de Vichy ? Paciencia y vivamos. // Al paso de la oca, / la svástica entra en el campo » [La almohada de arena, s.p.]. La visión de Aub es más compleja y valiosa. Cuando realiza la definición del comandante detentador del poder en el campo de Djelfa, lo describe como un cuerpo infectado y con los mismos síntomas que aquéllos a quienes encierra : piojoso, con sarna, podrido, que inútilmente, en principio, pretende trasladar a sus prisioneros las lacras negadas de su propia identidad : " no contagias, no, / esqueleto, verdugo en la mano, / pus, lepra, sarna / que nos quieres inficionar / a fuerza de trallas » [101]. El reverso es más trágico, porque en verdad Aub se ha dado cuenta de la dimensión que alcanza esta experiencia en el sentido apuntado por Naharro-Calderón cuando recuerda la identidad compartida de fascismo y colonialismo : " los atrapados entre alambradas no eran los supuestos "otros" chivos expiatorios del nazismo sino los "mismos" europeos de principios universales que los atrapadores, al menos retóricamente, conmemoraban en 1939 durante el ciento cincuenta aniversario de la Revolución " [1998b, 67]. Y Aub se sabe, en tanto que representante de este colectivo occidental, infectado, huésped forzoso de un espacio donde lo " cierto » ha sido reemplazado por lo " dudoso », por el " azar » [14], desplazado de toda geografia racional, en un " erramundos » [34] absurdo, en un desierto en el que, física y simbólicamente, « allá donde 
llega el ojo, / llega la nada » [43]. Es el lugar donde, como recoge el título de otro de sus poemas, todo ello se torna una trágica "Cuestión bizantina » [1819], pues también la palabra halla su límite y no consigue ni separarse del horror ni pararse ante la evolución espacio-temporal de este drama [NaharroCalderón, 1998b, 77]. Diario de Djelfa, como otros textos, ha de considerarse un indicador de esta fragilidad, de la supuración negada por la amnesia histórica y política de nuestro presente pero que no por ello deja de estar ahí, lacerada, testimoniando el otro lado de la cara amable y canónica.

Ello no impide la funcionalidad de la escritura, del poema, como un ejercicio de resistencia personal y colectivo, tal y como aclara perfectamente Aub en su prólogo al Diario de Djelfa : a estas poesías « les debo quizá la vida porque al parirlas cobraba fuerza para resistir al día siguiente », y su «valor [...] radica en otro plano : la desoladora epopeya del ejército español destrozado en los campos de concentración franceses y el hecho singular de sobrevivir en éstos la única esperanza de victoria que nuestros cómitres, con los medios que nos negaron, no supieron lograr " [7-8]. Amieva incluso manifiesta su confianza en el poder de la palabra literaria como vehículo de la memoria personal a través del tiempo, y describe el enterramiento de un manuscrito en la arena de Argelès cuyo contenido queda salvaguardado en el espacio de una memoria que lo habrá de recuperar más adelante : «Leve te sea la arena. / En verso habrás de renacer " [La almohada de arena, s.p. ; Ugarte, 1991]. Es esta dimensión la que justifica las alusiones a la patria como una posibilidad aún no derrotada, aunque sí dolorosamente perdida, en poemas como los de Aub o Amieva, alusiones que necesariamente conducen a la capacidad evocativa ejercida por la palabra. De este modo, frente a la negación espacial, temporal y de la identidad, Max Aub opone la incesante cadena repetitiva de la palabra 'España' como sustitución y mantenimiento lingüístico de la «España borrada del mapa » desde la victoria franquista producida tres años antes [34-35].

El uso de este último recurso conecta, desde su vocación descriptiva realista, con otro lugar común de estos escritos : la anulación de la palabra, la incapacidad del poema como vehículo transmisor del horror que nos sitúa en el límite usualmente citado, desde Adorno a Steiner, acerca del problema de la recreación lingüística ante la existencia del holocausto y la vía resolutiva del silencio. La dificultad de estos textos, que pretenden «territorializar la unidad de los espacios racionales», es necesariamente lingüística, porque « la sobrevivencia escrita de las vivencias de lo ilimitado se enfrenta a una doble paradoja : se requiere adaptarlas a un lenguaje, el 
cual según la tradición racionalista, limita el mundo de la experiencia. ¿Pero cómo referirse a los campos de concentración cuando son manifestaciones excluidas de esas limitaciones del lenguaje ? ", es una literatura, o un testimonio, que atenta contra la horizontalidad conformista de la sensibilidad burguesa para, mediante el ejercicio de propaganda que supone, concienciar e integrar verticalmente a sus receptores [Naharro-Calderón, 1998, 309-310]. Así nos lo recuerda Aub en el prólogo a Diario de Djelfa, los suyos son " versos inimaginados o inimaginables » [7]; o Manolo Valiente explica los efectos que este hecho tiene sobre el lenguaje : «Hablar no es nada, / La voz está hueca / Y llena de arena » $[1997,94)]$, y por eso muchos de sus poemas, al contrario que en Aub, tienden a rehuir la referencia al infierno presente para establecer un mundo paralelo y escapista creado por la imaginación poética.

En otros casos, el peligro del silencio se hace tema en sí mismo, como ocurre en Destierro de Teresa Gracia, un largo poema en que la meditación sobre esta vivencia se presenta con una inusual intensidad reflexiva que recupera la mirada infantil de su época en los campos franceses. Su inicio define con exactitud el alcance del problema al que se enfrenta el sujeto poético e histórico, pues es « una voz sin palabra que la capte », desorientado, sin saber "por qué hilo de su vida descolgarse » [17], que además es consciente del peligro que supone toda estética verbal ya que las « metáforas » pueden arrancar la « verdad ». Más aún, se es consciente de la capacidad olvidadiza de la memoria y de su expresión, pues esta voz desposeída « de caer, / no caería sino en la nada / para la que algún órgano me nacería / de forma que pueda seguir portándome / como quien soy o como acostumbro » [17]. Es la falsa propiedad regenerativa de un organismo sustentado en el vacío de la amnesia histórica que se intenta suplir con el arraigo en una tierra regada con el propio llanto y a la que se le pide " una limosna en cantos ». Frente al dolor, la búsqueda de la palabra : " entonces es cuando saco la lengua / hacia la tabla de salvación de alguna palabra... " [24], pero, paradójicamente, sólo la renuncia a esta palabra puede conducir a la salvación. Y este es el problema originario, el terreno en que se ha de abocar esta semilla es el suelo de Barcarès donde, como explica, « enterramos, / escribiéndolas en la arena, / aún con vida las palabras, / esperando ante el mar que el silencio desembarque / y alguien venga a cortar las alambradas » [22]. La liberación, como en Amieva, ha de pagar el precio del silencio, pero en este caso además se constata que el desposeído de su tierra, el exiliado, no puede conservar la palabra que de esta tierra emana 
pues pisa suelo extranjero. La voz originaria sólo puede habitar en el interior de la memoria, "entre lengua y alma " [27], incapaz de salir, de hacerse verbo : " entonces vas y te la vuelves a tragar " [27] . Permanece, por tanto, atragantada para que el «enemigo » no pueda cogerla, para que no quede despojada de la verdad que contiene al ser una palabra contaminada que se iguala con el pasado concentracionario y que, en tanto que prueba de la ignominia creada por los represores, es silenciada, negada, excluida en una típica técnica autodefensiva de todo discurso nacionalista [NaharroCalderón, 1998b, 70]. Así, los piojos que « subiendo fueron por las hebras de mi pelo » son como " las palabras que echo a andar : en busca de un rostro que el mar lavó para la muerte ", forman la misma unidad. Y por eso sólo se recupera este lenguaje cuando, rescatado " de algún rincón olvidado del cuerpo / (dedicado a enfermedad) ", se convierte en un " grito largo " y « hecho pedazos » en el cuerpo, igualmente enfermo, del poema [34]. Grito acusador, donde poema y tierra se funden, invaden el yo hasta aproximarlo al borde "del silencio de la rima ", hasta colmar el cuerpo de esa tierra que le ha sido negada y con ello hacer de la escritura presentización de lo olvidado, testimonio y transmisor de la infección : "Ya tengo la boca llena / de la tierra que pisáis... / Con la poca fuerza que me quede / os la escupiré a la cara / para que el grito / que en ella fuere / en el oído os dé. » [36-37].

Es la misma herida citada por Gil-Albert, la conexión purulenta de Aub, la boca desollada que escupe la arena del exilio una vez que ésta se ha hecho tierra en la memoria del desterrado. Pero es una herida que, como aprecia María Zambrano en su comentario del poemario de Gracia, y no otro es el sentido de la fisura abierta por estos poemas, está « destinada a no cerrarse nunca pues que ella en su radical entereza no podría dejarla cerrar en falso, es decir en vano, dándose el lujo de ofrecer el hueco propicio a la falacia. Mas las heridas no duran si no se ahondan, si no se purifican, si no cumplen

${ }^{7}$ En la misma línea tendría que situarse uno de los sentidos primarios de su pieza Las republicanas, cuya acción se desarrolla en «un campo de concentración francés para mujeres y niños españoles" [1984, 9]. La acotación inicial nos indica la dimensión simbólica de esta «tragedia » que es representada para "peces y navegantes ", unos peces que «se quieren ahogar sacando la cabeza al aire ", metáfora de la voz exiliada de aquéllos que han vivido una experiencia concentracionaria que supone el último suspiro del sujeto histórico asfixiado en la impostura de una Historia falsamente purificada y oxigenada: "Trátase, pues, del último suspiro, convertido en palabra, de quien está fuera de su elemento » [7]. 
una función vital, si no son heridas que atraviesan las diferentes capas del sentir y del pensar " [8].

\section{Bibliografía}

Alfaya, Javier, "Españoles en los campos de concentración nazis ", en José Luis Abellán (coord.), El exilio literario español de 1939. II. Guerra y política, Madrid, Taurus, 1976, p. 89-120.

Altolaguirre, Manuel, Obras completas, I. El caballo griego. Crónicas y artículos. Estudios literarios, edición crítica de James Valender, Madrid, Ediciones Istmo, 1986.

Amieva, Celso, La almohada de arena, México D.F., Ecuador $0^{\circ} 0^{\prime} 0^{\prime \prime}$, noviembre 1960.

- Poeta en la arena, México D.F., Ecuador 00'0', septiembre 1964.

Aub, Max, Diario de Djelfa. Obras incompletas de Max Aub, México D.F., Joaquín Mortiz, 1970.

Aznar Soler, Manuel, «1939: ética y estética de la solidaridad », Anthropos. Documentos A, 1 (enero 1991), p. 32-36.

Bauman, Zygmunt, Modernidad y holocausto [1989], tr. de Ana Mendoza, Madrid, Sequitur, 1997.

Bazal, Luis, Vaso de lágrimas : poemas de la guerra, poemas del exilio, poesía de la muerte, Toulouse, edición del autor, 1957.

Berman, Marshall, Todo lo sólido se disuelve en el aire. La experiencia de la modernidad [1982], tr. de Andrés Morea Leal, Madrid, Siglo veintiuno, 1991.

Candel Vila, Xelo, "Max Aub y la encrucijada poética. La ficción realista en el Diario de Djelfa », en Cecilio Alonso (ed.), Max Aub y el laberinto español. Actas del Congreso Internacional celebrado en Valencia y Segorbe del 13 al 17 de diciembre de 1993, Valencia, Ajuntament de Valencia, tomo II, 1996, p. 643-652.

Canosa Donate, José, Six roses noires pour une blanche, ilustraciones y adaptaciones al francés de Michel David, prefacio de Georges Blanchon, Isère (Grenoble), Comité France-Espagne de l'Isère, 1946.

- Antología poética, prefacio de Nery Bonneville, Grenoble, patronnée par l'Université de Langues et Lettres de Grenoble - Cercle Cervantès de Grenoble, 1974. 
Cohen, Monique-Lise y Malo, Eric (eds.), Les camps du sud-ouest de la France 1939-1944. Exclusion, internement et déportation, Toulouse, Éditions Privat, 1994.

Gil-Albert, Juan, Los días están contados, Barcelona, Tusquets, 1974.

- Memorabilia, Barcelona, Tusquets, 1975.

- Las ilusiones [1944], prólogo de Guillermo Carnero, Barcelona, Mondadori, 1998.

Guereña, Jacinto Luis, «Exilio y andadura creativa : Mi experiencia en las letras españolas y francesas ", en Manuel Aznar Soler (ed.), El exilio literario español de 1939. Actas del Primer Congreso Internacional (Bellaterra, 27 de noviembre-1 de diciembre de 1995), Sant Cugat del Vallès, Associació d'Idees-GEXEL, 1998, tomo II, p. 637-644.

Guillén, Jorge, Clamor. Tiempo de historia. Maremágnum, Buenos Aires, Sudamericana, 1957.

Gracia, Teresa, Destierro, prólogo de María Zambrano, Valencia, Pre-Textos, 1982.

- Las republicanas, Valencia, Pre-Textos, 1984.

López Casanova, Arcadio, "Creación poética y poética de ruptura. (Un acercamiento a la obra lírica de Max Aub) ", en Cecilio Alonso (ed.), Max Aub y el laberinto español. Actas del Congreso Internacional celebrado en Valencia y Segorbe del 13 al 17 de diciembre de 1993, Valencia, Ajuntament de Valencia, tomo II, 1996, p. 625-641.

Naharro-Calderón, José María, "Por los campos de Francia : entre el frío de las alambradas y el calor de la memoria », en Alicia Alted y Manuel Aznar Soler, (eds.), Literatura y cultura del exilio español de 1939 en Francia, Salamanca, AEMICGEXEL 1998, p. 307-325.

- « ¿Y para qué la literatura del exilio en tiempo destituido ? », en Manuel Aznar Soler (ed.), El exilio literario español de 1939. Actas del Primer Congreso Internacional (Bellaterra, 27 de noviembre - I de diciembre de 1995), Sant Cugat del Vallès, Associació d'Idees-GEXEL, 1998, tomo I, p. 63-83.

Rafaneau-Boj, Marie-Claude, Los campos de concentración de los refugiados españoles en Francia (1939-1945) [1993], Barcelona, Omega, 1995.

Rosenfeld, Alvin H., A Double Dying. Reflections on Holocaust Literature [1980], Bloomington e Indianápolis, Indiana University Press, 1988. 
Salaün, Serge, «Education et culture dans les camps de réfugiés », en Jean-Claude Villegas (coord.), Plages d'exil. Les camps de refugiés espagnols en France-1939, Hispanistica XX, Université de Bourgogne-BDIC Nanterre, 6, 1989, p. 117-124.

- «Las voces del exilio. La poesía española : 1938-1946 », en Josefina Cuesta y Benito Bermejo (coords.), Emigración y exilio españoles en Francia 19361946, Madrid, Eudema, 1996, p. 355-365.

Sánchez Barbudo, Antonio, Ensayos y recuerdos, Barcelona, Laia, 1980.

Serrano Plaja, Arturo, Los álamos oscuros, Barcelona, Plaza \& Janés, 1982.

Steiner, George, Lenguaje y silencio. Ensayos sobre la literatura, el lenguaje y lo inhumano [1967], tr. de Miguel Ultorio, Barcelona, Gedisa, 1982

Ugarte, Michel, "Testimonios de exilio : desde el campo de concentración a América ", en José María Naharro-Calderón (ed.), El exilio de las Españas en las Américas : " ¿Adónde fue la canción? ", Barcelona, Anthropos, 1991, p. 43-62.

Valiente, Manolo, Anthologie - Antología, introducción y selección de Narciso Alba, Perpignan, CRILAUP-Presses Universitaires de Perpignan, 1997.

Villegas, Jean-Claude (coord.), Plages d'exil. Les camps de refugiés espagnols en France-1939, Hispanistica XX, Université de Bourgogne-BDIC Nanterre, 6, 1989 